\title{
Editorial
}

\section{Origins of laryngology: from mirror to laser}

Laryngology, as a medical discipline originated in Vienna, between 1857 and 1859, thanks to an Austrian neurologist, Ludwig Turck, and a Czechoslovak physiologist, Johann Czermak, who introduced, to clinical studies, the most useful and efficacious means with to carry out indirect laryngoscopy: the laryngeal mirror invented, three years earlier, by the Maestro of song, Manuel Garcia.

Endoscopy, the possibility to observe in vivo the characteristics of the hidden organ, was the indispensable condition with which to develop new specialties such as rhinology, urology and also laryngology.

The earliest recorded reference, which is considered to be part of laryngology, is a drawing on the wall of the Doctor's Tomb in the step pyramids of Saqqara, Egypt, that dates from Circa 3600 B.C. The picture is presumed to depict a tracheotomy. According to ancient physicians, the trachea was assumed to be a conduit for blood. In India, medical knowledge was complied into Charaka (100 A.D) and Susruta (300 A.D), which included various remedies for disorders of the voice that suggest some knowledge of the larynx and throat as the source of the voice.

The first mention of the larynx was by the Aristotle (350 B.C) In the Historia Animulium (Book I, Chapter XII), he states, "The neck is the part between face and trunk (the front of this, is the larynx and the back, the gullet). Through the front part, speech and respiration take place and it is known as the wind-pipe". Erasistratos of Chioss (290 B.C) described the function of the muscles of larynx. Galen in Rome, 2nd century AD, in his treatise De usu partium corporis humini, discusses the functions of larynx.

Probably the earliest record of the tracheostomy dates to the time of Alexander, the great who is credited with saving the life of his gasping soldier with a single stroke of the tip of his sword made through the wind-pipe.

Leonardo Da Vinci in 1519, a genius of diverse interest and energy, dissected the human body and further detailed the functioning of the larynx. Giovanni Morgagni, in his "Adversaria Anatomica Prima" again, beautifully illustrated the larynx in fine details. Ferrein in 1741 finally coined the term vocal cords; he pic-tured the vocal cords as comparable to the strings of a violin activated by a stream of air. Bertin in 1745 pointed out that the structures were folds and not cords. Strangely enough, even though the official anatomic designation is vocal folds, late in the $20^{\text {th }}$ century, in clinical medicine these are still called vocal cords. After Darwin had shaken the scientific world with his publication of "Origin of the species", there was a general recognition of a semblance of order in nature, and this, in turn, led to a revision of thought about laryngeal function, and attention was directed to the primary reason d'etre of larynx, that is protection of the airway, by its sphincteric action.

In $19^{\text {th }}$ Century, infectious diseases of larynx were more common and more life threatening then malignancy. With the introduction of newer techniques for the examination of 
larynx, anatomy and the diseases were studied more widely.

Probably the most significant barrier to the development of laryngology was the inability to examine the larynx. In 1806, Bozzini fashioned an angled speculum with a mirror inserted for examination of various body cavities, which did not gain much popularity.

But it was Manunuel Garcia(1805-1906) a Spanish singing teacher first examined the larynx. In 1854 he had gone for a visit to France. In his own words "One September day in 1854, I was strolling in the garden of the Palais Royal, preoccupied with the everrecurring wish so often repressed as unrealisable, when suddenly I saw the two mirrors of the laryngoscope in their respective positions, as if actually present before my eyes. I went straight to Charriere, the surgical instrument maker, and asking if he happened to possess a small mirror with a long handle, was informed that he had a little dentist's mirror, which had been one of the failures of the London Exhibition of 1851. I bought it for six francs. Having obtained also a hand mirror, I returned home at once, very impatient to begin my experiments. I placed against the uvula the little mirror (which I had heated in warm water and carefully dried) and by flashing upon its surface with the hand mirror a ray of sunlight, I saw at once, to my great joy, the glottis wide open before me and so fully exposed that I could perceive a portion of the trachea.

When my excitement had somewhat subsided, I began to examine what was passing before my eyes. The manner in which the glottis silently opened and shut, and moved in the act of phonation, filled me with wonder.
He published his observation on human voice in proceeding of the Royal Society of London. Later on there were many attempts were made to examine larynx directly.

Turk started experimenting with laryngeal mirrors, but unfortunately he used sunlight and soon abandoned the technique because of the inherent difficulties. In 1857, Johann Czermak of Budapest borrowed Turk's mirrors for physiological study and with aid of artificial light, achieved much success. Although Turk should be credited with introducing indirect laryngoscope of clinical medicine, Czemark was responsible for its development and for popularizing the technique.

Sir Morrell Mackenzie of England, at this time became fascinated by the laryngeal examinations of Czermak. He redesigned the laryngeal mirror, then called it 'laryngoscope' and used round mirrors instead of squares. He also designed instruments for biopsy of the larynx by indirect laryngoscope. Mackenzie was skilled observer and obviously a superb technician.

In 1858 Cutter (Massachusetts) introduced laryngoscope with two tubes one for illumination and other for observation. Avery in 1840 invented perforated head mirror using a source of light (candle and laryngeal mirror) all of these things mounted on a head holder.

In 1874, the first clinic of laryngology was established in the Vienna General Hospital with Schrotter as the first surgeon who was the first surgeon who removed vocal polyp even before the discovery of local anes-thetic agents. Dr Horace Green (New York) was the first person who started Laryngology in USA. $\mathrm{He}$ introduced various types of brushes and sponges attached to probangs (flexible piece of whale bone). The American Laryngology Society was started in 1878. 
Gustar Killian of Mainz performed direct bronchoscopy in 1898. He introduced suspension laryngoscope in 1912. Chevalier Jackson of Philadelphia in 1915 revolutionized the examination of larynx by using light carrier with a bulb in laryngoscope. Jackson, with his tremendous enthusiasm, dexterity, and communica-tive skills, was largely responsible not only for horning endoscopy into a fine art, but also for considerably expanding its applications for diagnosis and treatment.

Gustav Killian, in Berlin, developed a direct laryngoscope and an apparatus for suspending the laryngo-scope. Later Lynch modified it and popularized it in the United States.

Burnings, in Germany and Jackson in the United States, used monocular magnification in the early 1950s. With the advent and universal popularity of the Zeiss operating microscope in the mid 1950s, binocular magnifi-cation was added to the Yankauer laryngoscope as redesigned by Jako (1970). In 1950's, it was Klinsausser to use microscope for laryngeal surgery.

Today, examination of the larynx has been developed into a fine art thanks to the pioneering creative work and expertise of $\mathrm{Dr}$. Karl Storz of Tuttlingen and Prof. H. H. Hopkins together, with the photographic techniques of Sir Bruce Benjamin.

The first application of lasers in laryngeal microsurgery was done by Jako in 1967 on a cadaveric larynx. The clinical application was commenced in 1972 when Strong and Jako presented their report on the use of $\mathrm{Co}_{2}$ laser on 12 patients.

Prof. Dr. Kamrul Hassan Tarafder, FCPS, FICS Professor, Otolaryngology - Head \& Neck Surgery, Bangabandhu Sheikh Mujib Medical University, Shahbag, Dhaka, Bangladesh. email: kamrul.hassan.tarafder@gmail.com

\section{References:}

1. Otolaryngology: An Illustrated History Neil Weir, Butterworths, London, 1990.

2. Biographical History of Medicine John H. Talbott, 1970.

3. "Sir Morel Mackenzie Revisited" Ned 1. Chalat Laryngoscope 1984; 94(10): 8490.

4. Morell Mackenzie R. Scott Stevenson, William Heinmann Medical Books Ltd., London, 1946.

5. The Fatal Illness of Frederick the Noble Morel Mackenzie, Sampson Low, Martson, Searle, and Rivington Ltd., London, 1888.

6. Strong MS, Jako GJ. Laser surgery in the larynx. Ann Oto Rhino Laryngol 1972; 81: 791-98.

7. Charaka et al. Journal of Indian Voice Association 2006; 1: 3-7.

8. Italian ORL Society Past and Present: Origins of Laryngology, May-2005. 